\title{
Research on Recovering Silver from Pregnant Solution by Zinc shavings Precipitation
}

\author{
Bin $\operatorname{Han}^{1,2,3,4}$, Xian Xie 1, 2, 3,, Xiong Tong ${ }^{1,2,3,4}$, Haozi Lv², 2, 4 \\ ${ }^{1}$ Faculty of Land Resource Engineering, Kunming University of Science and Technology, Kunming, \\ 650093, China \\ ${ }^{2}$ State Key Laboratory of Complex Nonferrous Metal Resources Clean Utilization, Kunming, \\ 650093, China \\ ${ }^{3}$ Yunnan Province Engineering Research Center for Reutilization of Metal Tailings Resources, \\ Kunming, 650093, China
}

${ }^{4}$ International Science \& Technology Cooperation Base for Comprehensive Utilization of Complex Mineral Resources in Yunnan Province, Kunming, 650093, China

Keywords: Pregnant Solution; Zinc shavings; Silver; Precipitation.

\begin{abstract}
At present, Cyanidation is still undoubtedly the most important and widespread of the various hydrometallurgical technologies that were used in the extraction of gold and silver from primary ores and concentrates, Metallic zinc has long been known as being a good precipitant for precious metals from cyanide solution. The technology of recovering silver from the cyanide solution by zinc shavings precipitation was studied in this paper. Experimental studies were carried out on the solution of silver cyanide, which contain $20.42 \mathrm{mg} / \mathrm{L}$ of silver and $277.9 \mathrm{mg} / \mathrm{L}$ of copper. The proposed procedure derived from this study is based on the dosage of zinc shavings 0.5g, soaking for 10 minutes in lead nitrate solution, a low temperature drying method for zinc shavings, and a replacement time of 10 minutes with pregnant solution, the replacement rate of Silver was 91.35\%.
\end{abstract}

\section{Introduction}

It is common knowledge that Silver is indispensable [1]. Silver is one of the earliest discovery and exploitation of metal elements in human. People have known natural silver about 5000-6000 years ago. In ancient times, silver has the highest electrical conductivity, thermal conductivity, ductility and plasticity, easy polishing and modelling, also with a number of metal alloy or false in all metal. Silver also has stronger performance of corrosion resistance, resistance to organic acid and alkali, in normal temperature and humidity is not easy to be oxidized. For a long time, a large amount of high purity silver used in the manufacture of silver and decorations. With the development of science and technology, silver has from the traditional currency and the arts and crafts of jewellery consumption, gradually transferred to the application and development of industrial technology. At present, from industrial use to decoration, technology, photography and medicine, its unique properties of strength, malleability, reflectivity and conductivity make it an irreplaceable force in the global market.

At present, Cyanidation is still undoubtedly the most important and widespread of the various hydrometallurgical technologies that were used in the extraction of gold and silver from primary ores and concentrates [2-5].There are many method of recovering silver from the solution of silver cyanide, such as zinc replacement precipitation, activated carbon adsorption, ion exchange resin, and solvent extraction directly. Metallic zinc has long been known as being a good precipitant for precious metals from cyanide solutions. According to the presently employed procedure, the solution of silver cyanide complex is first treated, as by vacuum, to remove free oxygen which is needed in conjunction with the alkali metal cyanide to dissolve the silver but which interferes with the subsequent precipitation with zinc. The deoxygenated solution is then treated with zinc shavings, usually for several hours and preferably overnight, to precipitate the silver and form a silver-zinc slurry. A small amount of lead acetate is usually added to help coagulate the silver-zinc slurry. Then 
the slurry is filtered, the filter cake is treated with acid to dissolve out the zinc and lead, and the mixture filtered again and the silver filter cake washed free of acid. But its use heretofore has been attended with many difficulties. Zinc threads or shavings have been used, but the cost thereof is high, the shavings soon become polarized and coated and require frequent washing in order to enable the process to be continued with any degree of success. There are many factors affecting the replacement by Zinc shavings in the solution of silver cyanide. When Silver is recovered from pregnant solution highly containing $\mathrm{Cu}, \mathrm{Pb}$ and $\mathrm{Zn}$ by zinc shavings precipitation, the effect is disappointing. Besides, the surface properties of zinc and the concentration of sodium cyanide played the important role in replacement by Zinc shavings [6-10].

Therefore, Research on recovering silver from pregnant solution by zinc duct precipitation can not only improve the economic performance, but also can benefit the society.

\section{Process background}

The pregnant solutions used in experiment were from the filtrate which was cyanide leaching Silver ores. During the study, analysis methods such as the chemical analysis and precipitation test were put to use.

\section{Chemical multielement analysis}

The purpose of Chemical multielement analysis is to identify the main elements of its components contents leaching pregnant solution, and determine the nature and characteristics of the solution. So the property of the Pregnant Solution was preliminary researched, make a spectral analysis and chemical compositions analysis. The results were as Table 1 . Chemical multielement analysis results show that $\mathrm{Ag}$ and $\mathrm{Zn}$ were the main valuable elements, the grade of $\mathrm{Ag}$ was $20.42 \mathrm{mg} / \mathrm{L}$, the grade of Zn was $405 \mathrm{mg} / \mathrm{L}$ and the content of Cu was $277.9 \mathrm{mg} / \mathrm{L}$ which was a harmful element on the replacement. The content of $\mathrm{Pb}$ and Fe was low.

Table 1 Chemical multielement analysis results of Pregnant Solution, mg/L

\begin{tabular}{cccccc}
\hline Component & $\mathrm{Ag}$ & $\mathrm{Pb}$ & $\mathrm{Cu}$ & $\mathrm{Fe}$ & $\mathrm{Zn}$ \\
\hline Content & 20.42 & 0.322 & 277.9 & 0.679 & 405 \\
\hline
\end{tabular}

\section{Experimental}

In the solution of silver cyanide, the standard potential of zinc is $-1.26 \mathrm{~V}$, but the standard potential of silver is $-0.31 \mathrm{~V}$. The standard potentials and equilibrium constants show that Zinc metal can be replaced easily with silver in the solution of silver cyanide and the $\mathrm{pH}$ of the solution does not affected in the replacement process of silver.

$$
2 \mathrm{Ag}(\mathrm{CN})^{2-}+\mathrm{Zn}=2 \mathrm{Ag}+\mathrm{Zn}(\mathrm{CN}) 4^{2-} \quad \mathrm{K}=1.37 \times 10^{32}
$$

The experiment is performed at normal temperature and pressure. Each test needs pregnant solution $30 \mathrm{~mL}$, soak zinc in the lead nitrate solution. The stirring speed is $450 \mathrm{r} / \mathrm{min}$. Every test is for a factor's effect test, dry filter, analysis of Ag concentration in solution. Effective factors such as dosage of zinc shavings, soaking time and replacement time and zinc shavings pre-treatment way after soak are examined. The flow sheets of Zinc replacement silver tests are shown in Fig.1.

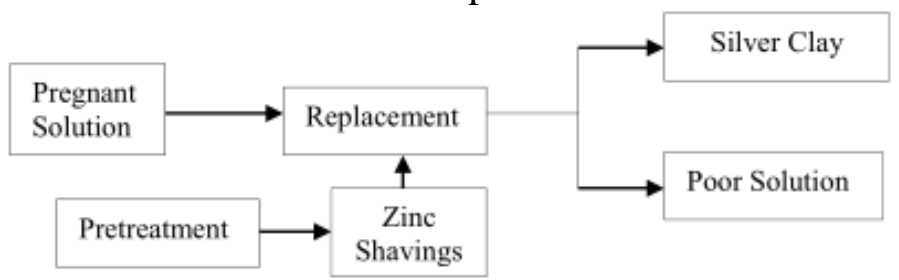

Fig.1 Flow sheet of Ag replacement test

\section{Results and discussion}

\section{Effect of dosage of zinc shavings on Replacement process}

In order to determine the dosage of displacer, the zinc shavings condition test is performed. The result was shown in Fig.1. It shows that with the dosage of zinc shavings increasing, replacement 
rate continues to improve. When the dosage of zinc shavings is up to $0.5 \mathrm{~g}$, it can obtain a better effect where the replacement rate is $69.12 \%$. At the same time, with the dosage of zinc shavings continuing to increase, the replacement rate of silver has a little difference. Considering the replacement rate and economic efficiency, therefore, the best dosage of zinc shavings is $0.5 \mathrm{~g}$.

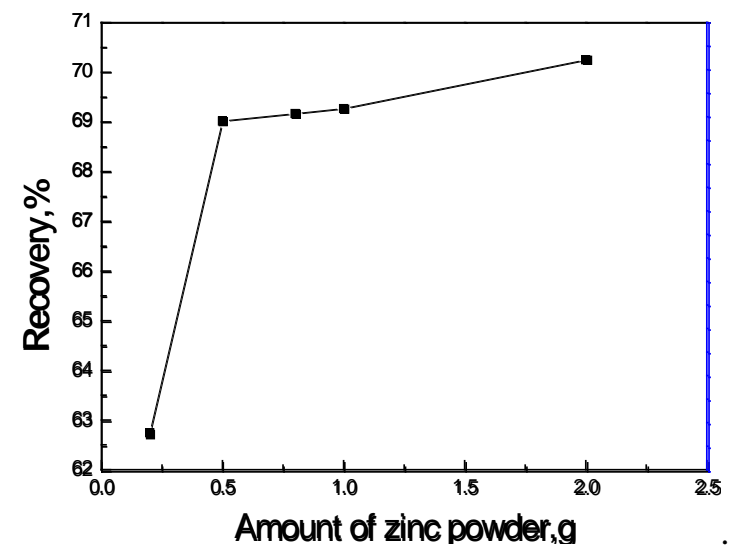

\section{Effect of soaking time on zinc shavings}

Fig .1 Relation between dosage and recovery of Ag

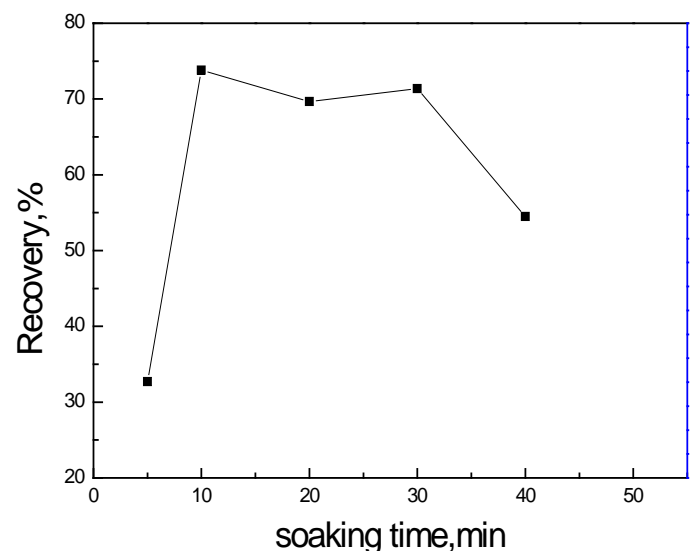

Fig .2 Relation between soaking time and recovery of Ag

The test results in Fig .2 shown that soaking time is too long or too short are bad for the sliver replacement ,following the zinc shavings soaking time increase, the replacement rate of $\mathrm{Ag}$ in the solution first increasing and then decrease, in the 10 to 30 min soaking time, the silver replacement have a little difference, in order to improve the efficiency, the soaking time keep in $10 \mathrm{~min}$ is the perfect time.

\section{Effect of replacement time on zinc shavings}

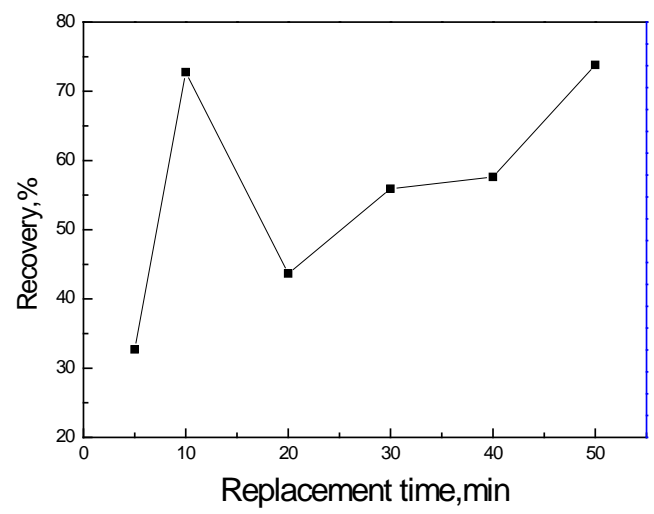

Fig. 3 Relation between replacement time and recovery of Ag

The result of the replacement time was shown in Fig.3. It shows that with extending the replacement time within 10 minutes, the Silver's replacement rate increases. The highest Silver's replacement rate of $72.77 \%$ occurred at $10 \mathrm{~min}$ replacement time. As time continues to lengthen, the 
speed of Silver's replacement rate was decreased. Therefore, in consideration of the cost and other factors, determine the optimal replacement time for 10min.

\section{Effect of zinc shavings pretreatment way after soak}

By the test can determine the optimal dosage of zinc powder is $0.5 \mathrm{~g}$, zinc powder soak for 10 minutes, displacement time of 10 minutes, get the best replacement rate was $73 \%$, therefore, conventional displacement process substitution rate is not high, large fluctuations, so after soaking zinc powder are further processing, in order to improve the displacement rate of silver. The results were as Fig. 4.

According to the results shown in Fig. 4, Subsequent processing of zinc after soaking has a great impact on the replacement rate, especially the low-temperature drying and filtration process using water for cleaning can greatly increase the replacement ratio of silver. The highest replacement rate Occurred in low-temperature drying but relative difficulty of the operation. Operation easier of filtration process using water for cleaning, but the replacement rate is relatively low point. Besides, high-temperature drying may make the surface of the lead-zinc oxide inactivation, so that reducing the replacement rate instead.

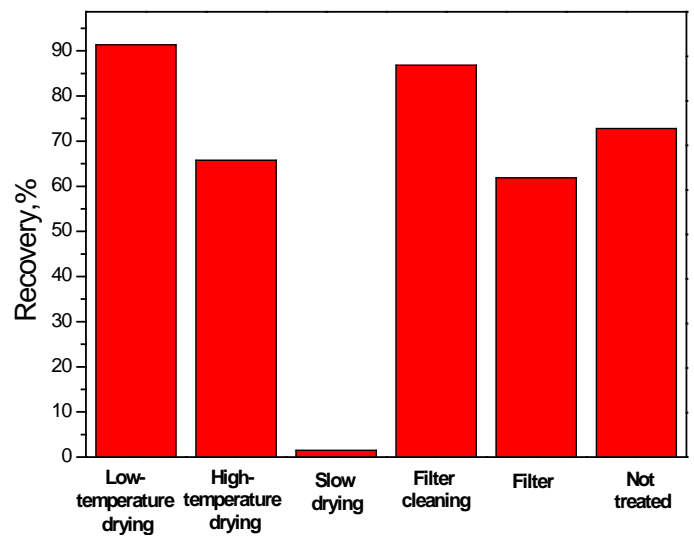

Fig. 4 Relation between Pretreatment and recovery of Ag

\section{The verification test}

The result of replacement by zinc shavings test shows that when choose the dosage of zinc shavings $0.5 \mathrm{~g}$, soaking for 10 minutes in lead nitrate solution, a low temperature drying method for zinc dust, and a replacement time of 10 minutes with pregnant solution, the replacement rate can be $91.35 \%$.

Table 2 the results of the verification test

\begin{tabular}{ccc}
\hline Product & $\mathrm{Ag} / \mathrm{mg} / \mathrm{L}$ & Recovery/\% \\
\hline After reaction & 1.767 & \multirow{2}{*}{91.35} \\
\hline Pregnant Solution & 20.42 & \\
\hline
\end{tabular}

Table 3 Analysis of Chemical multielement after test, mg/L

\begin{tabular}{cccccc}
\hline Component & $\mathrm{Ag}$ & $\mathrm{Pb}$ & $\mathrm{Cu}$ & $\mathrm{Fe}$ & $\mathrm{Zn}$ \\
\hline Content & 1.767 & 5.02 & 263.40 & 0.064 & 473 \\
\hline
\end{tabular}

We could not only clearly understood the different effects on zinc ion replacement process, but also could grasped the content of other ions and providing a theoretical basis for the recovery of other ions through the Chemical multielement analysis of the solution of silver cyanide after test. Chemical multielement analysis results after test was shown in Table 3. According to the results, the zinc and lead ions in the solution was increased significantly, but the iron ions reduced greatly. The results show that the entire displacement process is mainly the result of the associative action of zinc and lead, and the copper ion and iron ion in the salt solution has a certain influence on the displacement, especially to the displacement of zinc powder which has not been soaked. It may because that iron ion and copper ion compete with silver ion to have the displacement with zinc 
powder. With copper and iron ion covering on the surface of zinc, the effective activity of zinc powder will be reduced, thus affecting the displacement efficiency of zinc powder.

\section{Conclusions}

Optimum process conditions for zinc dust replacement: the optimum dosage of zinc is $0.5 \mathrm{~g}$, soaking for 10 minutes in lead nitrate solution, a low temperature drying method for zinc dust, a replacement time of 10 minutes with pregnant solution. At this point, the best replacement rate was $72.77 \%$.

After soaking zinc powder and the best condition, different processing technology on exchange rate is greatly influenced. Which in the process of low temperature drying and filtration of the zinc powder again after cleaning by water displacement can greatly improve liquid boc's replacement rate.

The verification test under optimal conditions show that the replacement rate of silver was satisfactory. Through a verification test, a good replacement results that $91.35 \%$ recovery has been achieved.

\section{Acknowledgements}

The authors are thankful to the financial support from the Join Foundation the National Natural Science Foundation Committee of China (Grant No.51174103) and Kunming University of Science Analysis and Testing Facility (Grant No. 20140879).

\section{References}

[1] World Silver Survey, 2005. GFMS Limited/ the Silver Institute. (http://www.silverinstitute.org).

[2] Gamini Senanayake. The cyanidation of silver metal: Review of kinetics and reaction mechanism: Hydrometallurgy, 81(2), p. 75-85, 2006.

[3] Peter Baláž, Jana Ficeriová, Carlos Villachica Leon. Silver leaching from a mechanochemically pretreated complex sulfide concentrate: Hydrometallurgy, 70(1-3), p. 113-119, 2003.

[4] Jared L. Deutsch, David B. Designer. Silver sulfide leaching with thiosulfate in the presence of additives Part I: Copper-ammonia leaching: Hydrometallurgy, 137(1), p. 156-164, 2013.

[5] D.M. Puente-Seller, J.C. Fuentes-Acetone, F. Nava-Alonso. A kinetic-thermodynamic study of silver leaching in thiosulfate-copper-ammonia-EDTA solutions: Hydrometallurgy, 134(1), p. 124131, 2013.

[6] H.V.Michaells, G F Xu. Recovery of gold and silver from the leaching liquid

A dust replacement, charcoal, and ion exchange and regeneration Hydrometallurgy, 1(4), p. 50-55, 1989.

[7] His key, J.B. gold and silver heap leaching operations. In: His key, J.B. (Ed.), Au and Ag Heap and Dump Leaching Practice. AIME, (1983) p. 1-7.

[8] Feng Xie, David B. Designer. Leaching of silver sulfide with ferricyanide- cyanide solution: Hydrometallurgy, Vol. 88 (2007) No.1, p. 98-108.

[9] Charles H Urquhart. Process of precipitating and recovering metals, US1090661 a (1914).

[10] Charles Davidoff: Silver recovery process, US3311468 A (1967). 